Article

\title{
Unpacking Plastic: Investigating Plastic Related Ambivalence
}

\author{
Lena Hahn, Benjamin Buttlar* and Eva Walther
}

Department of Psychology, University of Trier, 54286 Trier, Germany; hahnl@uni-trier.de (L.H.); walther@uni-trier.de (E.W.)

* Correspondence: buttlar@uni-trier.de; Tel.: +49-651-201-3009; Fax: +49-651-201-3804

check for

updates

Citation: Hahn, L.; Buttlar, B.; Walther, E. Unpacking Plastic: Investigating Plastic Related Ambivalence. Sustainability 2021, 13, 2186. https://doi.org/10.3390/ su13042186

Academic Editor: Cameron Brick Received: 9 December 2020 Accepted: 13 February 2021 Published: 18 February 2021

Publisher's Note: MDPI stays neutral with regard to jurisdictional claims in published maps and institutional affiliations.

Copyright: (c) 2021 by the authors. Licensee MDPI, Basel, Switzerland. This article is an open access article distributed under the terms and conditions of the Creative Commons Attribution (CC BY) license (https:// creativecommons.org/licenses/by/ $4.0 /)$.

\begin{abstract}
Many people are aware of the negative consequences of plastic use on the environment. Nevertheless, they use plastic due to its functionality. In the present paper, we hypothesized that this leads to the experience of ambivalence-the simultaneous existence of positive and negative evaluations of plastic. In two studies, we found that participants showed greater ambivalence toward plastic packed food than unpacked food. Moreover, they rated plastic packed food less favorably than unpacked food in response evaluations. In Study 2, we tested whether one-sided (only positive vs. only negative) information interventions could effectively influence ambivalence. Results showed that ambivalence is resistant to (social) influence. Directions for future research were discussed.
\end{abstract}

Keywords: ambivalence; plastic; MouseTracker; intervention

\section{Introduction}

Plastic can be found almost everywhere: it is even in the human body [1]. In humans, higher plastic concentrations are related to type two diabetes [2,3], heart disease [4,5], and endocrine changes [6]. Most often, plastic enters the human body through food sources by migrating from packaging to food [7]. However, even if people eat food that is not packed in plastic, it can still be found in the human body [8]. Since commonly used plastics are not biodegradable [9], plastic that has been released into the environment remains there. For example, it exists as debris in the oceans [10], and as micro- or nanoparticles in the air [11], agricultural soils [12], and water supplies [13]. Thus, plastic can also enter the human body due to inhalation of plastic particles in the air, as well as through the consumption of plants which have absorbed it, and fish which have swallowed it.

Not only does the disposal and durability of plastic threaten human and animal health, its whole lifecycle aggravates climate change. In 2019, the greenhouse gas emissions of the plastic lifecycle were 850 million metric tons [14], which is more than the total yearly greenhouse gas emissions of Germany (e.g., 808.73 million metric tons in 2016; [15]).

Despite these critical arguments, plastic production has quadrupled over the past four decades [9]. According to statisticians, if this trend continues, the greenhouse gas emissions from plastic could comprise 15\% of the global carbon budget by 2050 [16]. If it does not change, this trend will make limiting the global temperature rise to $1.5^{\circ} \mathrm{C}$ nearly impossible [14].

In order to counteract the environmental and health threats caused by plastic, reduced plastic production and consumption are essential [14]. In the present work, we focus on the latter, specifically plastic consumption in cases in which unpacked alternatives are relatively easily accessible (e.g., fresh food).

\subsection{Ambivalence Regarding Plastic}

In their literature review, Heidbreder et al. [17] found that overall plastic is perceived as an environmental risk but is used due to its light weight, transparency, resistance, and convenience. Therefore, people may simultaneously have favorable and unfavorable evaluations toward plastic. This psychological co-occurrence of positive and negative 
evaluations toward the same object is known as ambivalence [18]. Attitudes toward plastic may be considered as ambivalent because plastic also has positive aspects despite its wideranging negative consequences for the environment and human health. In fact, Zwicker et al. [19] demonstrated that people's attitude toward plastic consists of positive and negative associations with plastic: the positive associations include aspects like considering plastic to be cheap, useful, or lightweight, as well as emotions, with people indicating that they feel joy or excitement when thinking about plastic. The negative associations include considerations such as plastic being harmful to animal and human health and causing waste, and emotions such as guilt and worry felt by people when they think about plastic. If the positive and negative evaluations merely co-occur without inducing conflict, this is referred to as potential ambivalence [20]. Indeed, Zwicker et al. [19] found initial evidence for plastic-related ambivalence: compared to bio-based plastic, conventional plastic had significantly higher self-reported potential ambivalence. Thus, plastic is a prime example of an ambivalent attitude object.

Potential ambivalence, however, does not necessarily affect behavior, cognition, and affect [18]. In fact, only if people are confronted with making a choice (e.g., do I buy plastic packed mushrooms or unpacked mushrooms) people actually experience conflict (i.e., felt ambivalence) which affects behavior, cognition, and affect [20]. While it is possible to measure potential and felt ambivalence with self-report questionnaires, these measures are prone to error (e.g., lack of introspection; [21]) and can produce statistical artifacts [22]. To avoid these problems, felt ambivalence can be measured via the MouseTracker paradigm [21,23]. It requires participants to make a choice (i.e., evaluate the attitude object as positive vs. negative) while the mouse movements are recorded. Thus, felt ambivalence captures ambivalence-induced conflict.

Because ambivalence is reflected in a conflict, it is often conceptualized as an indicator of attitude strength, with higher ambivalence indicating weaker attitudes [24]. Weaker attitudes are usually considered to be less predictive of behavior intentions [25]. Consistently, previous research has shown that ambivalence moderates the attitude-intention relationship predicted by the theory of planned behavior [26-28]. In this way, ambivalence might be the starting point for developing interventions: weaker attitudes should be more pliable to influence [24].

In accordance with this hypothesis, Armitage and Conner [25] found that a persuasive message influenced people more when they were ambivalent toward its topic. Furthermore, Russel et al. [29] showed that one-sided arguments that match the context of the attitude object have a bigger influence than non-matched arguments. Here, we argue that arguments that are consistent (inconsistent) with the evaluation of the object should decrease (increase) ambivalence. For example, if an ambivalent person evaluates plastic rather negatively and receives information about the negative aspects of plastic (consistent), plastic-related ambivalence should decrease. Contrarily, if the same person only receives information about the positive aspects of plastic (inconsistent), plastic-related ambivalence should increase.

\subsection{The Present Investigation}

In the present investigation, we aimed to examine whether plastic induces ambivalence and whether this ambivalence can be changed via one-sided information interventions. In two studies, we measured felt ambivalence toward plastic packed and unpacked food via the MouseTracker paradigm [21,23]. In Study 2, we tried to influence plastic-related ambivalence via one-sided text interventions. Both studies were approved by the ethics committee of the University (No. 17/2019) and were pre-registered before data collection was started. Supplementary materials include pre-registrations, materials, data, and analysis scripts for both studies and is available on OSF https:/ / osf.io/zyshj/. 


\section{Study 1}

In Study 1, we aimed to demonstrate that plastic elicits felt ambivalence. We hypothesized that people exhibit more ambivalence if they evaluate food packed in plastic than if they evaluate unpacked food.

\subsection{Method}

\subsubsection{Participants and Design}

We recruited 55 participants ( 6 men, 49 women, $M_{\text {age }}=20.98$, age range $=18-48$ years). Participants were university students and received course credits for participation. Study 1 was conducted as a one-factor (plastic, no plastic) within-subject design. Based on studies by Schneider and colleagues [21], who found a medium sized effect $(d=0.45,95 \%$ confidence interval (CI) $[0.23,0.68]$ ) for ambivalent vs. non-ambivalent stimuli, we conducted an a priori power analysis. This repeated measure ANOVA sample size calculation via G*Power 3.1 [30] with $f=0.25$, a correlation of $r=0.5$, a power of $1-\beta=0.95$, and $\alpha=0.05$, revealed a sample size of $N=54$ participants. A slightly larger sample was achieved due to active participation. The data analyses were conducted after the collection of all data.

\subsubsection{Materials and Procedure}

The study was conducted in a lab and lasted approximately half an hour. Participants were seated in soundproof cubicles with a chair, a desk, a flat screen computer (Eizo FlexScan S1911, 1280×1024), a QWERTZ keyboard, and a computer mouse in front of them. A total of six participants could participate at the same time. First, the participants were informed that the study was about thought processes and personal assessments, and that they had to perform a categorization task in which they evaluate various objects. Then, they were asked to give informed consent to participate in the study.

Afterwards, the study started and the participants completed the MouseTracker paradigm [23]. With the MouseTracker paradigm [23] it is possible to track real-time processing by recording the mouse movement as well as the response (i.e., evaluation as positive vs. negative). The degree of ambivalence and univalence, as well as neutrality, can be captured in mouse movements [21,31]. In order to reduce variance in the target pictures while also ensuring visibility of the products, pictures of food (cucumber, white mushrooms, iceberg lettuce, brown mushrooms, tomatoes, broccoli, beetroot, pointed cabbage, chinese cabbage, corn) either packed in transparent plastic or unpacked were used. This resulted in a total of 20 target pictures. We used 40 pictures from the Food Pics database [32] as distractors. The target and distractor pictures did not differ in size.

A trial started with the appearance of a start button presented at the bottom middle of the screen and the two response buttons (positive vs. negative) at the top right and top left corner of the screen. The site of the response button was balanced between participants. Thus, half of the participants had the positive button on the right and the negative button on the left, while this was reversed for the other half of the participants. Because the results did not differ, the data were collapsed. After clicking the start button, a picture appeared in the middle of the screen while the mouse was centered at the bottom middle of the screen. The response was indicated by moving the mouse and clicking on the chosen response button. After the response, the picture disappeared and a new trial started. If participants took longer than $1000 \mathrm{~ms}$ to start moving the mouse, they were instructed to move earlier, even if they were not sure about their response. Trials with reaction times faster than $300 \mathrm{~ms}$ and trials with reaction times slower than $3000 \mathrm{~ms}$ were excluded (in both studies these accounted for less than $1.5 \%$ of all trials; [21]). After five training trials, participants completed two blocks of trials. In each block participants rated the randomly presented target and distractor pictures, resulting in two ratings for all pictures.

A mouse movement has less pull to the unselected response for univalent evaluations compared to ambivalent evaluations. Therefore, an ambivalent evaluation results in a curved line [21]. Most often, maximum deviation (MD) is used to operationalize the pull of the mouse toward the unselected response. A bigger MD is expected for ambivalent than 
for univalent products (see Figure 1). The response measures positive or negative button press and indicates the percentage of positive evaluations.
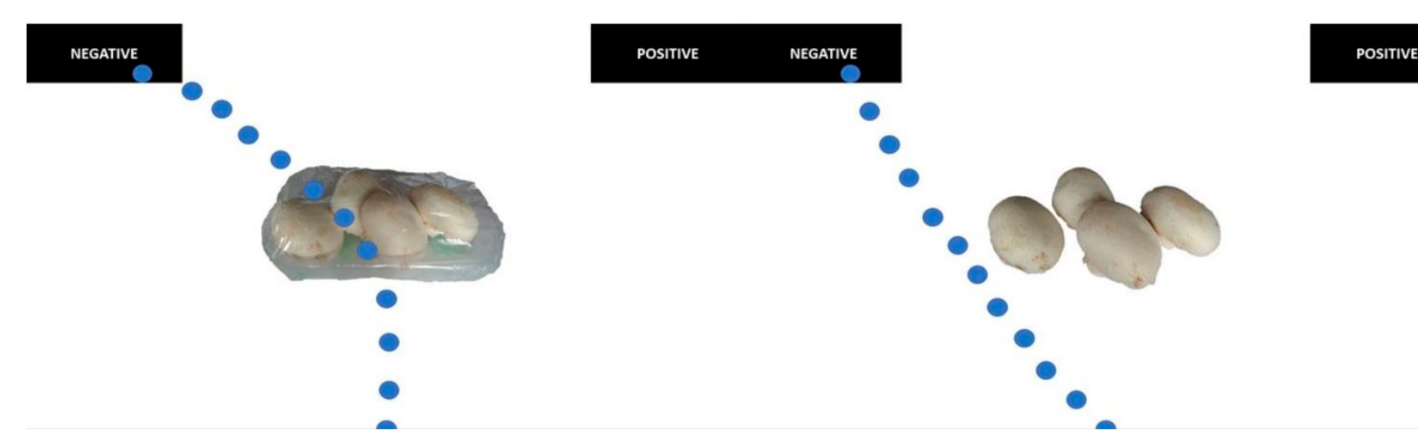

Figure 1. Illustration of the MouseTracker paradigm with plastic packed and unpacked food. The blue dots illustrate the mouse movement but were not presented to participants. Both panels depict a negative response. The left panel illustrates a trial where the mouse trajectory is pulled toward the non-chosen option (ambivalent) and the right panel illustrates a trial where the mouse trajectory is not pulled toward the non-chosen option (univalent).

After completing the MouseTracker, participants answered demographic questions (age, sex, field of study, handedness). For exploratory purposes, they also filled out an extended theory of planned behavior questionnaire about plastic packaging (adapted from [33]). The questionnaire included subscales on attitude toward plastic packaging, subjective norm, perceived behavioral control, intention to use plastic packaging, convenience, environmental concern, and ethical beliefs. Note that the exploratory analyses were inconclusive and are not reported because the power was insufficient to test mediation and moderation hypotheses. Finally, they were thanked and debriefed.

\subsection{Results}

All analyses were conducted with IBM SPSS Statistics for Windows (Version 26).

\section{MouseTracker Paradigm}

In order to test the pre-registered hypothesis that pictures of plastic packed food elicit more ambivalence than pictures of unpacked food, we conducted a one-factor (plastic, no plastic) repeated measure ANOVA with the dependent variable MD. The main effect was significant, $F(1,54)=11.37, p=0.001, \eta_{p}{ }^{2}=0.17,95 \%$ CI $[0.03,0.34]$. As hypothesized, people were drawn more toward the non-chosen option if they evaluated food packed in plastic $(M=0.22, S D=0.18)$ compared to unpacked food $(M=0.14, S D=0.12)$. This implies that people experience greater ambivalence and that their response is literally torn when evaluating food packed in plastic compared to unpacked food.

A one-factor (plastic, no plastic) repeated measure ANOVA with the dependent variable response (percentage of positive evaluation) was conducted to investigate the general direction of the evaluations. This analysis revealed that food packed in plastic was rated as significantly less positive $(M=0.24, S D=0.31)$ than unpacked food $(M=0.79$, $S D=0.22), F(1,54)=122.7, p<0.001, \eta_{p}^{2}=0.69,95 \%$ CI $[0.55,0.78]$. That is, people evaluated pictures of unpacked food as positive in $79 \%$ of the trials, while they evaluated pictures of plastic packed food as positive in only $24 \%$ of the trials.

\subsection{Discussion}

In this study, we found that people experience more ambivalence if they evaluate food packed in plastic than if they evaluate unpacked food. We took this as a first indication that addressing this ambivalence might be a good lever to reduce intentions for plastic use. 


\section{Study 2}

Study 1 provided confirming evidence that people hold ambivalent attitudes toward plastic. In the next step, we investigated whether plastic-related ambivalence can be changed through interventions. In line with Russel et al. [29], we implemented text interventions stressing either the positive or the negative sides of plastic packaging for food. The intervention design was completed by a control condition providing information unrelated to plastic.

Even though ambivalence includes the co-occurrence of positive and negative evaluations toward an attitude object [18], (ambivalent) participants in Study 1 responded mostly negatively to plastic packed food. This indicates that when people have to make decisions, the negative associations toward plastic dominate. Therefore, we argue that giving negative information about plastic should decrease ambivalence. Contrarily, giving positive information about plastic should increase ambivalence. That is, we expected that if people read a text about the positive aspects of plastic (being inconsistent with the response), they would exhibit more ambivalence than people reading a control text or people reading a text about the negative aspects of plastic. Contrarily, if people read a text about the negative aspects of plastic (being consistent with the response), we expected them to exhibit less ambivalence than people reading a control text or people reading a text about the positive aspects of plastic.

\subsection{Method}

\subsubsection{Participants and Design}

A total of 101 (87 women, 14 men, $M_{\mathrm{age}}=21.08$, age range $=18-32$ years) students participated in the study and received course credits for their participation. Students who participated in Study 1 were excluded prior to their participation. Study 2 was conducted in a 3 (intervention: positive, negative, control) $\times 2$ (packaging: plastic, no plastic) within-between participant design with repeated measures on the last factor. An a priori within-between ANOVA sample size calculation via $G^{*}$ Power 3.1 [30] with $f=0.25$, a correlation of $r=0.5$, a power of $1-\beta=0.95$, and $\alpha=0.05$, for three groups and two measurements was calculated. For the between factor effect, this analysis resulted in a minimum of $N=189$, and for the within-between interaction, this analysis resulted in a minimum of $N=66$ participants. As pre-registered, the data collection was terminated on December 6th, 2019. All data analyses were conducted after the collection of the data.

\subsubsection{Materials and Procedure}

Study 2 took place in the same lab setting as Study 1 . The design of this study was similar to Study 1, except for the intervention before the MouseTracker paradigm [23] and the manipulation check at the end of the study.

\section{Intervention}

One group received a text about positive aspects of plastic packaging around food (positive), another group read a text about the negative aspects of plastic packaging around food (negative) and a control group read a text about a resource called Lignin without referring to plastic (control). The texts were approximately the same length (the text about the positive aspects of plastic had one word less than the texts about the negative aspects of plastic or the control text) and were adapted from the website PLASTIKALTERNATIVE [34,35].

\section{Manipulation Check}

Participants received a pen and paper questionnaire with a free recall question about the content of the text. Additionally, they indicated their agreement to three statements on a $100 \mathrm{~mm}$ long scale ranging from 0 to 100 with the endpoints labeled "I do not agree" and "I do agree". The first 25 participants had a questionnaire with a slightly longer explanation on how to use the scale. Due to a technical error, the last 25 participants received a 
manipulation check questionnaire with slightly shorter scales (98 $\mathrm{mm}$ ), the data of these participants was transformed (answer of participant* 1.02) so that it was equivalent to the participants answering on the $100 \mathrm{~mm}$ scale. Even though missing values were theoretically possible, this case did not occur. The statements were: "The content of the text is positive." (Item 1), "The content of the text is negative." (Item 2), and "The content of the text is credible." (Item 3). Afterwards, they were thanked for their participation and debriefed.

\subsection{Results}

All analyses were conducted with IBM SPSS Statistics for Windows (Version 26).

\subsubsection{Manipulation Check}

Three participants were excluded from the pre-registered analysis because they incorrectly recalled the content of the intervention text. The results of Item 1 and Item 2 were in the expected direction (see Supplementary Materials for detailed analyses). Critically, the one-factor (intervention: positive, negative, control) ANOVA for Item 3 was significant, $F(2$, $95)=17.27, p<0.001, \eta_{p}{ }^{2}=0.27,95 \%$ CI $[0.12,0.39]$. Bonferroni adjusted pairwise comparison revealed that the participants reading the negative text rated the text as significantly more credible than participants reading the positive text $\left(p<0.001, d_{Z}=1.4,95 \%\right.$ CI [0.85, 1.94]) or the control text $\left(p<0.001, d_{Z}=1.31,95 \%\right.$ CI $\left.[0.77,1.83]\right)$. Participants reading the positive text and participants reading the control text did not differ in their credibility ratings $(p=0.62)$.

\subsubsection{MouseTracker Paradigm}

The Shapiro-Wilk tests were significant, however, our group sizes are almost equal and degrees of freedom are high. Thus, the ANOVAs should be robust against this violation [36]. In order to investigate the impact of the intervention on ambivalence, a 3 (intervention: positive, negative, control) $\times 2$ (packaging: plastic, no plastic) withinbetween ANOVA, with repeated measurement on the second factor and MD as dependent variable was conducted. The analysis revealed a main effect of packaging, $F(1,95)=10.03$, $p=0.002, \eta_{p}{ }^{2}=0.1,95 \%$ CI $[0.01,0.22]$, indicating more ambivalence in plastic packed food $(M=0.23, S D=0.21)$ than in unpacked food $(M=0.13, S D=0.2)$. All other $F \mathrm{~s}<1$, and all other $p s>0.05$. Thus, contrary to the hypothesis, the intervention did not influence felt ambivalence.

For the response a 3 (intervention: positive, negative, control) $\times 2$ (packaging: plastic, no plastic) within-between ANOVA with repeated measurement on the second factor revealed a main effect of packaging, $F(1,95)=550.87, p<0.001, \eta_{p}{ }^{2}=0.85,95 \%$ CI $[0.8,0.89]$. Participants evaluated plastic-packed food less positively $(M=0.13, S D=0.24)$ compared to unpacked food $(M=0.87, S D=0.2)$. Thus, participants positively evaluated plastic packed food in $13 \%$ and unpacked food in $87 \%$ of the trials. The main effect of intervention did not reach significance $(p=0.27)$. The interaction of packaging and intervention did not reach significance, $F(2,95)=2.74, p=0.069, \eta_{p}{ }^{2}=0.06,95 \%$ CI $[0.00,0.15]$.

\subsection{Discussion}

The results of Study 2 replicated the findings of the previous study, that plastic elicits ambivalence. This ambivalence was, however, not influenced by the intervention, indicating that ambivalence might not be as pliable as hypothesized. However, results of the marginal significant interaction of packaging and intervention in responses indicated that the intervention had at least some influence on participants' ratings.

\section{General Discussion}

Plastic can be found (almost) everywhere, even in humans [1]. It is contained in a lot of objects that we use in everyday life (i.e., bottles, food packaging, clothing) as it is easy to use and highly versatile. Unfortunately, plastic also poses a great threat to human health and the environment [11]. This ambivalence is reflected in people's attitudes 
toward plastic, including positive and negative aspects as well as positive and negative emotions [19]. In the present investigation, we argued that this ambivalence may affect the attitude-intention link [26-28]. Based on this, we hypothesized that targeting ambivalence could be an effective intervention strategy to reduce plastic use intention [25].

We conducted two studies testing whether plastic elicits felt ambivalence and whether this ambivalence can be changed via one-sided information interventions. In Study 1, data supported the hypothesis that plastic effectively induces ambivalence: plastic packed food elicited more felt ambivalence than unpacked food. This highlights the need to acknowledge that attitude objects can elicit strong positive and strong negative evaluations at the same time.

In Study 2, we investigated ambivalence as a leverage point for interventions. We tested whether one-sided information interventions can affect ambivalence-which in turn should influence intention to use plastic. Based on Study 1 and the findings of Russel et al. [29], we hypothesized that positive information about plastic packaging (being inconsistent with people's responses) would increase plastic-related ambivalence, and negative information about plastic packaging (being consistent with people's responses) would decrease plastic-related ambivalence. This assumption, however, was not supported by the data.

One factor explaining why the intervention did not influence ambivalence could be people's prior knowledge. People might already be aware of the positive and negative aspects, rendering the intervention ineffective. Consistently with this hypothesis, Sawicki et al. [37] found that participants expected attitude-consistent new information to decrease ambivalence whilst they expected attitude-inconsistent new information to increase ambivalence. Thus, if the information given in the text interventions was already known, ambivalence should not differ between interventions. Nonetheless, the texts for the interventions were matched with the context of the stimuli (plastic packed food) and the manipulation check indicated that people at least processed the information provided. Thus, ambivalence toward plastic might not be as pliable as expected.

In addition, a strong connection between moral values and attitude toward plastic might account for the lack of effectiveness of the intervention. Previous research suggests that plastic use and according intentions are strongly associated with moral beliefs $[33,38]$. For example, Sun et al. [33] found that the higher the ethical beliefs were, the lower was the intention to use plastic and the less favorable was the attitude toward plastic. This indicates that attitudes toward plastic and plastic use have a strong moral basis. Research indicates that such morally grounded attitudes are more resistant to persuasion [39], and lead to a higher correspondence between attitude and according intention [40]. It could thus be speculated that any information in our intervention lead people to reflect on their attitudes toward plastic. Thereby, the moral issues that people associate with it could have become salient independently from intervention conditions. This could potentially explain why the interventions were ineffective.

\subsection{Future Studies}

So far, however, studies yielded mixed results on whether stressing moral issues in interventions is advantageous. In fact, interventions that aim to strengthen moral norms to reduce plastic use have not been effective so far [41]. This is somewhat surprising because moral transgressions (e.g., using plastic) should lead to guilt, and guilt is known to motivate pro-environmental intention as well as actual behavior [42]. In line with this, Zwicker et al. [19] found that guilt is central in plastic perception and has a strong connection to behavior. In one of their studies, they found that a text intervention was able to induce experienced guilt, leading people to donate to a sustainable cause.

Thus, we propose that some people are able to deny that plastic use is a moral transgression and, consequently, do not experience guilt. For instance, Atkinson and Kim [43] found that people justify their plastic consumption via two moral disengagement strategies: denial of responsibility and denial of injury. Denial of responsibility frees people 
from their responsibility, for example, the perceived lack of alternatives leaves consumers with no choice but to purchase products packed in plastic. Denial of injury diminishes the harm caused by plastic consumption, for example, by rationalizing that other products have even more plastic packaging, so purchasing a product that is packed in plastic, but not overpacked, is justified. These strategies allow people to selectively disengage their behavior from their moral standards and indulge in immoral behavior without feeling guilty [44].

Therefore, keeping people morally engaged might trigger behavior change. In order to do this, it might not only be important to raise people's awareness for issues regarding plastic (as in our study) but linking people's individual and specific actions to the negative outcome. In accordance with this view, a two-stage intervention to reduce meat consumption - another prime example of ambivalence-not only led to a less favorable attitude toward meat but also to less willingness to eat meat [45]. That is, the first stage consisted of information and the second stage of a dialog designed to counteracting moral disengagement (e.g., denial of responsibility). In a similar vein, identifying additional moral disengagement strategies and counteracting them could be an effective way to combat plastic use.

\subsection{Limitations}

At first glance, our results may be interpreted to mean that packaging around food in general, rather than plastic packaging in particular, is perceived as negative and induces ambivalence. In fact, we only compared pictures of plastic packed and unpacked food. While this interpretation is valid, we deliberately chose these options. In fact, other packaging materials, like paper or cotton, do not offer suitable comparisons to test our hypotheses, as they also harm the environment-perhaps even more than plastic. For instance, paper or cotton carrier bags might be perceived as more environmentally friendly because they are fully biodegradable. However, taking the whole lifecycle into account, a paper bag would have to be reused 43 times, and conventional cotton bags 7100 times, to have a similar environmental impact than that of an average plastic carrier bag [46]. Moreover, we believe it is a strength of our experimental design that the stimuli were identical concerning size except for the transparent plastic package. This high comparability could not have been achieved by using other (non-transparent) packaging such as paper or cotton bags.

It should also be noted that the manipulation check for our intervention indicated differences in the credibility of the manipulation. Participants who read the negative text (consistent with responses) rated the text as more credible compared to participants who read the other text interventions. Even though this might suggest that the negative intervention should be more effective, it was not. We did not find an effect of the intervention on plastic-related ambivalence.

\section{Conclusions}

Like many other stimuli in the world, plastic elicits ambivalent attitudes. In both studies, we found that plastic triggered felt ambivalence. This ambivalence, however, seems to be persistent and not easily influenced. Considering the connection between ambivalence and morality, moral disengagement might explain people's guilt free plastic use. Thus, future research should identify plastic-related moral disengagement strategies. Interventions counteracting these strategies might lead to reduced plastic use, which is necessary in order to keep plastic out of the environment and human bodies.

Supplementary Materials: The pre-registration, materials, data, and analysis scripts for both studies are available online at https:/ / osf.io/zyshj/.

Author Contributions: Conceptualization, L.H.; methodology, L.H. and B.B.; software, L.H. and B.B.; formal analysis, L.H.; investigation, L.H.; resources, E.W.; data curation, L.H. and B.B.; writingoriginal draft preparation, L.H., B.B. and E.W.; writing-review and editing, L.H., B.B. and E.W.; 
visualization, L.H.; supervision, E.W.; project administration, E.W. All authors have read and agreed to the published version of the manuscript.

Funding: The publication was funded by the Open Access Fund of Universität Trier and the German Research Foundation (DFG) within the Open Access Publishing funding program.

Institutional Review Board Statement: Not applicable.

Informed Consent Statement: All participants gave their informed consent for inclusion before they participated in the studies.

Data Availability Statement: All data are available in the Supplementary Materials.

Conflicts of Interest: The authors declare no conflict of interest.

Ethics Statements: Both studies were approved by the ethics committee of the university (No. 17/2019).

\section{References}

1. FAO/WHO. Toxicological and Health Aspects of Bisphenol A. Report of Joint FAO/WHO Expert Meeting 2-5 November 2010 and Report of Stakeholder Meeting on Bisphenol A 1 November 2010. Available online: https://apps.who.int/iris/bitstream/ handle/10665/44624/97892141564274_eng.pdf?sequence=1\&isAllowed=y (accessed on 7 August 2020).

2. Rancière, F.; Botton, J.; Slama, R.; Lacroix, M.Z.; Debrauwer, L.; Charles, M.A.; Roussel, R.; Balkau, B.; Magliano, D.J.; D.E.S.I.R. Study Group. Exposure to Bisphenol A and Bisphenol S and Incident Type 2 Diabetes: A Case-Cohort Study in the French Cohort D.E.S.I.R. Environ. Health Perspect. 2019, 127, 107013. [CrossRef]

3. Song, Y.; Chou, E.L.; Baecker, A.; You, N.-C. Y.; Song, Y.; Sun, Q.; Liu, S. Endocrine-disrupting chemicals, risk of type 2 diabetes, and diabetes-related metabolic traits: A systematic review and meta-analysis. J. Diabetes 2015, 8, 516-532. [CrossRef]

4. Cai, S.; Rao, X.; Ye, J.; Ling, Y.; Mi, S.; Chen, H.; Fan, C.; Li, Y. Relationship between urinary bisphenol a levels and cardiovascular diseases in the U.S. adult population, 2003-2014. Ecotoxicol. Environ. Saf. 2020, 192, 1103000. [CrossRef]

5. Melzer, D.; Rice, N.E.; Lewis, C.; Henley, W.E.; Galloway, T.S. Association of Urinary Bisphenol A Concentration with Heart Disease: Evidence from NHANES 2003/06. PLoS ONE 2010, 5, e8673. [CrossRef]

6. Galloway, T.; Cipelli, R.; Guralnik, J.; Ferrucci, L.; Bandinelli, S.; Corsi, A.M.; Money, C.; McCormack, P.; Melzer, D. Daily Bisphenol A Excretion and Associations with Sex Hormone Concentrations: Results from the InCHIANTI Adult Population Study. Environ. Health Perspect. 2010, 118, 1603-1608. [CrossRef]

7. Geens, T.; Aerts, D.; Berthot, C.; Bourguignon, J.-P.; Goeyens, L.; Lecomte, P.; Maghuin-Rogister, G.; Pironnet, A.-M.; Pussemier, L.; Scippo, M.-L.; et al. A review of dietary and non-dietary exposure to bisphenol-A. Food Chem. Toxicol. 2012, 50, 3725-3740. [CrossRef]

8. Galloway, T.S.; Baglin, N.; Lee, B.P.; Kocur, A.L.; Shepherd, M.H.; Steele, A.M.; Harries, L.W. An engaged research study to assess the effect of a 'real-world' dietary intervention on urinary bisphenol A (BPA) levels in teenagers. BMJ Open 2018, 8, 29431133. [CrossRef] [PubMed]

9. Geyer, R.; Jambeck, J.R.; Law, K.L. Production, use, and fate of all plastics ever made. Sci. Adv. 2017, 3, 1-5. [CrossRef] [PubMed]

10. Lebreton, L.; Egger, M.; Slat, B. A global mass budget for positively buyant microplastic debris in the ocean. Sci. Rep. 2019, 9, 12922. [CrossRef] [PubMed]

11. Azoulay, D.; Villa, P.; Arellano, Y.; Gordon, M.; Moon, D.; Miller, K.; Thompson, K. Plastic and Health: The Hidden Costs of a Plastic Planet; Center for International Environmental Law: Washington, DC, USA, 2019; Available online: https://www.ciel. org/wp-content/uploads /2019/02/Plastic-and-Health-The-Hidden-Costs-of-a-Plastic-Planet-February-2019.pdf (accessed on 7 August 2020).

12. Hurley, R.R.; Nizzetto, L. Fate and occurrence of micro(nano)plastics in soils: Knowledge gaps and possible risks. Curr. Opin. Environ. Sci. Health 2018, 1, 6-11. [CrossRef]

13. Mintenig, S.M.; Löder, M.G.L.; Primpke, S.; Gerdts, G. Low numbers of microplastics detected in drinking water from ground water sources. Sci. Total Environ. 2019, 648, 631-635. [CrossRef]

14. Hamilton, L.A.; Freit, S.; Muffett, C.; Kelso, M.; Rubright, S.M.; Bernhard, C.; Schaeffer, E.; Mood, D.; Morris, J.; Labbé-Bellas, R. Plastic \& Climate The Hidden Costs of a Plastic Planet; Center for International Environmental Law (CIEL): Washington, DC, USA, 2019; Available online: https:/ / www.ciel.org/wp-content/uploads/2019/05/Plastic-and-Climate-FINAL-2019.pdf (accessed on 3 September 2020).

15. Ritchie, H.; Roser, M. Greenhouse Gas Emissions. OurWorldindata.org 2017. Available online: https: / / ourworldindata.org/ greenhouse-gas-emissions\#annual-greenhouse-gas-emissions-how-much-do-we-emit-each-year (accessed on 2 December 2020).

16. World Economic Forum. The New Plastic Economy: Rethinking the Future of Plastics; Ellen MacArthur Foundation, McKinsey \& Company: Cowes, UK, 2016.

17. Heidbreder, L.M.; Bablok, I.; Drews, S.; Menzel, C. Tackling the plastic problem: A review on perceptions, behaviors, and interventions. Sci. Total Environ. 2019, 668, 1077-1093. [CrossRef] [PubMed]

18. Van Harreveld, F.; Nohlen, H.U.; Schneider, I.K. Chapter Five-The ABC of Ambivalence: Affective, Behavioral, and Cognitive Consequences of Attitudinal Conflict. Adv. Exp. Soc. Psychol. 2015, 52, 285-324. [CrossRef] 
19. Zwicker, M.V.; Nohlen, H.U.; Dalege, J.; Gruter, G.-J. M.; van Harreveld, F. Applying an attitude network approach to consumer behaviour towards plastic. J. Environ. Psychol. 2020, 69, 101433. [CrossRef]

20. Van Harreveld, F.; Van der Pligt, J.; de Liver, Y.N. The agony of ambivalence and ways to resolve it: Introducing the MAID model. Personal. Soc. Psychol. Rev. 2009, 13, 45-61. [CrossRef]

21. Schneider, I.K.; van Harreveld, F.; Rotteveel, M.; Topolinski, S.; van der Pligt, J.; Schwarz, N.; Koole, S.L. The path of ambivalence: Tracing the pull of opposing evaluations using mouse trajectories. Front. Psychol. 2015, 6, 996. [CrossRef] [PubMed]

22. Ullrich, J.; Schermelleh-Engel, K.; Böttcher, B. The Moderator Effect That Wasn't There: Statistical Problems in Ambivalence Research. J. Personal. Soc. Psychol. 2008, 95, 774-794. [CrossRef] [PubMed]

23. Freeman, J.B.; Ambady, N. MouseTracker: Software for studying real-time mental processing using a computer mouse-tracker method. Behav. Res. Methods 2010, 42, 226-241. [CrossRef]

24. Conner, M.; Armitage, C.J. Attitudinal ambivalence. In Frontiers of Social Psychology. Attitudes and Attitude Change; Crano, W.D., Prislin, R., Eds.; Psychology Press: Tucson, AZ, USA, 2008; pp. 261-286.

25. Armitage, C.J.; Conner, M. Attitudinal Ambivalence: A Test of Three Key Hypotheses. Personal. Soc. Psychol. Bull. 2000, 26, 1421-1432. [CrossRef]

26. Conner, M.; Sparks, P.; Povey, R.; James, R.; Shepherd, R.; Armitage, C. Moderator effects of attitudinal ambivalence on attitude-behavior relationships. Eur. J. Soc. Psychol. 2002, 32, 705-718. [CrossRef]

27. Conner, M.; Poves, R.; Sparks, P.; James, R.; Shepherd, R. Moderating role of attitudinal ambivalence within the theory of planned behaviour. Br. J. Soc. Psychol. 2003, 42, 75-94. [CrossRef]

28. Cooke, R.; Sheeran, P. Moderation of cognition-intention and cognition-behaviour relations: A meta-analysis of properties of variables from the theory of planned behaviour. Br. J. Soc. Psychol. 2004, 43, 159-186. [CrossRef]

29. Russell, C.A.; Hamby, A.M.; Russell, D.W. When a correction contradicts: Countermessages may increase adolescents' ambivalence in response to drinking-related narratives. J. Advert. 2018, 47, 395-411. [CrossRef]

30. Faul, F.; Erdfelder, E.; Lang, A.G.; Buchner, A. G*power 3: A flexible statistical power analysis program for the social, behavioral, and biomedical sciences. Behav. Res. Methods 2007, 39, 175-191. [CrossRef] [PubMed]

31. Schneider, I.; Mattes, A. Mix is Different from Nix: Mouse Tracking differentiates ambivalence from neutrality 2021. J. Exp. Soc. Psychol. 2019. [CrossRef]

32. Blechert, J.; Meule, A.; Busch, N.A.; Ohla, K. Food-pics: An image database for experimental research on eating an appetite. Front. Psychol. 2015, 5, 617. [CrossRef]

33. Sun, Y.; Wang, S.; Li, J.; Zhao, D.; Fan, J. Understanding consumers' intention to use plastic bags: Using an extended theory of planned behavior model. J. Int. Soc. Prev. Mitig. Nat. Hazards 2017, 89, 1327-1342. [CrossRef]

34. Alternativen zu Plastik: Lignin. Flüssiges Holz-Ein Rohstoff mit Potenzial, Plastikalternative 2019. Available online: https: / / www.plastikalternative.de/alternativen-zu-plastik-lignin/ (accessed on 5 November 2019).

35. Plastik Vorteile im Überblick. Mal Anders betrachtet: Die Vorteile und der Nutzen von Plastik, Plastikalternative 2018. Available online: https:/ / www.plastikalternative.de/plastik-vorteile/ (accessed on 5 November 2019).

36. Lunney, G.H. Using analysis of variance with a dichotomous dependent variable: An empirical study. J. Educ. Meas. 1970, 7, 263-269. [CrossRef]

37. Sawicki, V.; Wegener, D.T.; Clark, J.K.; Fabrigar, L.R.; Smith, S.M.; Durso, G.R.O. Feeling Conflicted and Seeking Information: When Ambivalence Enhances and Diminishes Selective Exposure to Attitude-Consistent Information. Personal. Soc. Psychol. Bull. 2013, 39, 735-747. [CrossRef]

38. Nabila, Y.; Nurcahyo, R.; Farizal. The Key Factors in Reducing the Use of Plastic Bags. In Proceedings of the 2020 IEEE 7th International Conference on Industrial Engineering and Application (ICIEA), Bangkok, Thailand, 16-21 April 2020; pp. 197-201. [CrossRef]

39. Luttrell, A.; Petty, R.E.; Briñol, P.; Wagner, B.C. Making it moral: Merely labeling an attitude as moral increases its strength. J. Exp. Soc. Psychol. 2016, 65, 82-93. [CrossRef]

40. Judge, L.W.; Bellar, D.; Petersen, J.; Lutz, R.; Gilreath, E.; Simon, L.; Judge, M. The attitudes and perceptions of adolescent track and field athletes toward PED use. Perform. Enhanc. Health 2012, 1, 75-82. [CrossRef]

41. Heidbreder, L.M.; Schmitt, M. Fasting plastic: An intervention study to break habits of plastic consumption (Ayuno de plástico: Una intervención para cambiar los hábitos de consume de plásticos). PsyEcology 2020, 11, 170-192. [CrossRef]

42. Rees, J.H.; Klug, S.; Bamberg, S. Guilty conscience: Motivation pro-environmental behavior by inducing negative moral emotions Clim. Chang. 2014, 130, 439-452. [CrossRef]

43. Atkinson, L.; Kim, Y. "I drink it anyway and I know I shouldn't": Understanding green consumers' positive evaluations of norm-violating non-green products and misleading green advertising. Environ. Commun. 2015, 9, 37-57. [CrossRef]

44. Bandura, A. Moral Disengagement in the Perpetration of Inhumanities. Personal. Soc. Psychol. Rev. 1999, 3, 193-209. [CrossRef] [PubMed]

45. Buttlar, B.; Rothe, A.; Kleinert, S.; Hahn, L.; Walther, E. Food for Thought: Investigating Communication Strategies to Counteract Moral Disengagement Regarding Meat Consumption. Environ. Commun. 2021, 15, 55-68. [CrossRef]

46. Bisinella, V.; Albizzati, P.F.; Astrup, T.F.; Damgaard, A. Life Cycle Assessment of grocery carrier bags. Danish Environmental Protection Agency, Miljoeprojekter 2018. Available online: https:/ /www2.mst.dk/Udgiv/publications/2018/02/978-87-93614-7 3-4.pdf (accessed on 19 January 2021). 